\title{
Acknowledgement to Referees
}

(c) The Author(s) 2017. This article is an open access publication

Dear Reader,

The end of 2017 is quickly approaching, marking the close of Drug Safety_Case Reports' fourth volume. 2017 was a successful year for Drug Safety-Case Reports with more articles published online than last year; the most popular of these, in terms of downloads from SpringerLink as at September 2017, have been:

- Physicians' Experiences as Patients with Statin Side Effects: A Case Series Hayley J. Koslik, Athena Hathaway Meskimen, Beatrice Alexandra Golomb

- Hazardous Drug Diversion of Valproate from a General Practitioner to his Patient's Dog Pierre-Marie Morice, Joachim Alexandre, Alexandre Cesbron, Marion Sassier, Sophie Fedrizzi, Xavier Humbert

- Psychomotor Agitation Following Treatment with Hydroxychloroquine Ciro Manzo, Pietro Gareri, Alberto Castagna

- Drug Reaction with Eosinophilia and Systemic Symptoms (DRESS) with Teicoplanin: A Case Report Sholeh Ebrahimpour, Mehdi Mohammadi, Kheirollah Gholami

- How to Diagnose Early 5-Azacytidine-Induced Pneumonitis: A Case Report Srimanta Chandra Misra, Laurence Gabriel, Eric Nacoulma, Gérard Dine, Valentina Guarino

- Muscle Injury After Intramuscular Administration of Diclofenac: A Case Report Supported by Magnetic Resonance Imaging Mareike Probst, Jens-Peter Kühn, Christiane Modeß, Eberhard Scheuch, Anne Seidlitz, Norbert Hosten, Werner Siegmund, Werner Weitschies

- Atypical Fracture of the Sternum After Long-Term Alendronate Plus Cholecalciferol Treatment: A Case Report Luis H. Martín Arias, Pilar García Ortega, María Sáinz Gil, Ester Navarro García, Carlos Treceño Lobato, Virginia Delgado Armas

- Reversible Hypokalemia and Bartter-Like Syndrome during Prolonged Systemic Therapy with Colistimethate Sodium in an Adult Patient Tarek Kamal Eldin, Grazia Tosone, Alfredo Capuano, Raffaele Orlando

- Tracheo-Esophageal Fistula (TEF) in a Newborn Following Maternal Antenatal Exposure to Olanzapine Vikas Maharshi, Indranil Banerjee, Pravesh Nagar, Harmeet Singh Rehan

- Dabigatran-Induced Massive Spontaneous Hemothorax Jing Huang, Wei Lin, Dan Lv, Li Yu, Lun Wu, Haiying Jin, Zaichun Deng, Qunli Ding

Other journals in the Adis Premier Journals Portfolio (http://www.springer.com/gp/adis) continue to prosper, and this year has seen the successful launch of PharmacoEconomics-Open, the newest journal in the portfolio. The journal has published a full volume of 30 articles in its first year, plus many more online first. Following in the steps of Adis' flagship subscription journal in the field, PharmacoEconomics, the new open-access journal focuses on cost and health outcomes associated with drugs, devices and other healthcare interventions.

We thank the authors who have contributed articles to Drug Safety_Case Reports over the course of 2017. The skill and dedication of all authors are critical to the continued publication of the journal. The quality of published articles is also testament to the significant efforts of our peer reviewers, whose commitment ensures that the journal's content is held to the highest possible standard. We would like to thank the following individuals who have acted as reviewers for Drug Safety-Case Reports over the last 12 months: 


\begin{tabular}{|c|c|}
\hline Christopher Alderman, Australia & Shaheen Lakhan, USA \\
\hline Hakim Azfar Ali, USA & Regent Lee, UK \\
\hline Ion Anghelescu, Germany & Jo Ann LeQuang, USA \\
\hline Sevim Bavbek, Turkey & Unax Lertxundi, Spain \\
\hline Steven Belknap, USA & James Lewis, USA \\
\hline Jean-Marie Berthelot, France & Jeffrey Livezey, USA \\
\hline Mario Bonomini, Italy & Gloria Manso, Spain \\
\hline Rami Bou Khalil, Lebanon & Maja Mockenhaupt, Germany \\
\hline Carla Carnovale, Italy & Jean-Louis Montastruc, France \\
\hline Robert Chilton, USA & Ion Motofei, Romania \\
\hline Philip Cohen, USA & Agnik Pal, India \\
\hline Mario de Lemos, Canada & Ragesh Panikkath, USA \\
\hline Arianna Deidda, Italy & Tejas Patel, India \\
\hline Shadmehr Demehri, USA & Einat Peles, Israel \\
\hline Moses Elisaf, Greece & Bianca Maria Piraccini, Italy \\
\hline Yusuf Haydar Ertekin, Turkey & Natalia Popowicz, Australia \\
\hline Joseph Gabriel Gabriel, USA & Victoria Pratt, USA \\
\hline Pietro Gareri, Italy & Silvina Pugliese, USA \\
\hline Pedro Gaspar da Costa, Portugal & Satish Ramkumar, Australia \\
\hline Sophie Gosselin, Canada & Harriet Gail Rosenberg, Canada \\
\hline Kulothungan Gunasekaran, USA & Christoph Schempp, Germany \\
\hline David Herndon, USA & Jitendra Singh, India \\
\hline Ivan Fan Ngai Hung, Hong Kong & Anna Tai, Australia \\
\hline Risto Huиpponen, Finland & Gurvinder Pal Thami, India \\
\hline Paola Imbrici, Italy & Eugene van Puijenbroek, the Netherlands \\
\hline Matilde Iorizzo, Switzerland & Michael Veve, USA \\
\hline Seçil Kepil Özdemir, Turkey & Shan Yin, USA \\
\hline Arjun Khanna, India & Jonathan Zipursky, Canada \\
\hline
\end{tabular}

Evelien Kuiper-Prins, the Netherlands

In addition, we would like to thank the members of the journal's Honorary Editorial Board, who have acted as peer reviewers and authors, and have provided guidance on journal content, policy and processes:

Felix Arellano, Switzerland

Jeffrey Aronson, England

Brian Baldo, Australia

Jo Barnes, New Zealand

Ian Boyd, Australia

Peter Michael Brooks, Australia

Paola Cutroneo, Italy

Richard Day, Australia

Ivor Ralph Edwards, Sweden

Neila Fathallah, Tunisia

Robin Ferner, UK

Carmen Ferrajolo, Italy

Antonis Goulas, Greece

Bernard Guillot, France

Raquel Herrera Comoglio, Argentina

Judith Jones, USA
Jimmy Jose, Oman

David Juurlink, Canada

Joan-Ramon Laporte, Spain

Emmanuel Okoro, Nigeria

Samir Kumar Praharaj, India

Elizabeth Roughead, Australia

Muhammad Wasif Saif, USA

Ruth Savage, New Zealand

Rashmi Shah, UK

Rachida Soulaymani Bencheikh, Morocco

Rolf Teschke, Germany

Thierry Trenque, France

Gianluca Trifirò, Italy

Jack Uetrecht, Canada

Florence van Hunsel, the Netherlands 
We hope that you have found the articles published in Drug Safety - Case Reports this year to be both interesting and informative. We are looking forward to bringing you many more high-quality, authoritative articles in 2018.

With best regards,

Steve McMillan \& Nitin Joshi

Editors

Open Access This article is distributed under the terms of the Creative Commons Attribution-NonCommercial 4.0 International License (http:// creativecommons.org/licenses/by-nc/4.0/), which permits any noncommercial use, distribution, and reproduction in any medium, provided you give appropriate credit to the original author(s) and the source, provide a link to the Creative Commons license, and indicate if changes were made. 